\title{
Experiences from in-situ monitoring of pavement under weather conditions change
}

\author{
Barbara Likar ${ }^{1, a}$, Stanislav Lenart ${ }^{1}$, Karmen Fifer Bizjak ${ }^{1}$ and Anh Minh Tang ${ }^{2}$ \\ ${ }^{1}$ Slovenian National Building and Civil Engineering Institute, Dimiceva ulica 12, 1000 Ljubljana, Slovenia \\ ${ }^{2}$ Ecole des Ponts ParisTech, U.R. Navier/CERMES, 6-8 av. Blaise Pascal, Cité Descartes, Champs-sur-Marne, 77455 Marne-la-Vallee, \\ France
}

\begin{abstract}
Very strong winters with temperatures under $0^{\circ} \mathrm{C}$ and hot summers with temperatures more than $30^{\circ} \mathrm{C}$ are observed in the South East part of Slovenia. Those big differences in temperature during the year and especially temperatures below freezing point have strong influence on asphalt layer and sub base of road pavement. The freeze/thaw cycles lead to formation of ice lenses in base course causing cracks in asphalt layers and degrade the pavement usually in a few years. For this reason one section of the national road in the South East part of Slovenia was rebuilt with cold in-situ pavement retreatment. A test field with inbuilt sensors for measuring water content, temperature and deformation in various depths and locations was constructed during the remediation works to study the mechanism of freeze-thaw degradation of pavements. The main goal of the test field is to determine water content in sub base, freezing depth, temperature distribution and deformations, which lead to cracks in asphalt layer after the remediation work in the road construction.
\end{abstract}

\section{Introduction}

The main purpose of constructing test field for monitoring water content, temperatures and deformations in retreatment pavement was to observe changes in freezing depth according to cold in-situ retreatment layer with foamed bitumen and cement.

In Slovenia, normal pavement construction for National road in the area with potential presence of freezing consists of two layers above the undisturbed ground soil: (i) the sub base layer in thickness of $0.50 \mathrm{~m}$ with of freezing resistant gravel $0 / 90 \mathrm{~mm}$; (ii) and the base layer in thickness of $0.20 \mathrm{~m}$ with of gravel $0 / 32 \mathrm{~mm}$ with prescribed granulation. Asphalt layer, of a thickness depending on the traffic load, is above the base layer. Many roads are damaged according to fouled base layer. With an aim to find cost-effective and durable remediation technology, which retains the existing structure of pavement and adds only a new asphalt layer, cold in-situ retreatment with foamed bitumen and cement was adapted.

Many authors present the effects of climate on soil strength as well as pavement dependence on climate, soil type, drainage and depth of ground water table $([1,3,7])$. Most investigations can be divided into two main groups: determining moisture and temperature effect on pavement strength or determining freeze-thaw cycle effect on pavement strength. Moisture content and temperature variations change the deformation properties of unbound material ([7]), which leads to variations mainly continuous annual decrease of permanent deformation and settlements. Also soil temperature as an important parameter for prediction of freezing and thawing period, is affected by weather conditions, its properties, water content, loading and surface conditions ([12, 13, 14]). Pavement stiffness rapidly decreases during spring thaw, which causes large settlements ([14]), while during freezing no changes in settlement of road surface are observed ([14]). However spring thawing and snow melting can increase water content in base or sub base layer to saturated state, which also leads to reduction of pavement strength, decreasing dry density and increasing the porosity $([2,8,10])$.

The effects of freezing and thawing on sub base and recycled layer of pavement were investigated in the presented paper. Monitoring of water content, temperature distribution and strains in sub base and recycled layer of the reconstructed pavement of national road in Slovenia is presented hereafter.

\section{Description of the test field}

The test field is located in the South East part of Slovenia, on the national road Črmošnjice - Črnomelj: R1-216/1178 at kilometre $4+490$ right, in the town

a Corresponding author: barbara.likar@zag.si 
Vrčice. The test field was constructed in November 2011 during the remediation work in the road construction. The remediation was done by in-situ cold retreatment with foamed bitumen and cement in depth of $30 \mathrm{~cm}$. During the remediation works, soil was sampled in the locations of sensor installation for the purpose of field characterisation. Figure 1 shows the soil profile in the studied section with all installed sensors. The thickness of the recycled layer is about $0.30 \mathrm{~m}$. The old sub base layer consists of silty gravel in thickness of $0.48 \mathrm{~m}$ and gravel with clay in thickness of $0.10 \mathrm{~m}$. The sub grade consists of dolomite gravel, mainly clayish. No ground water was found during the excavation. The pavement construction is buried under the natural ground surface. The field instrumentation was done based on the field characterisation with sensors for temperature, water content and horizontal strains. Sensors were installed in recycled layer and in old sub base layer in two horizontal positions: near the wheel tracks and near the middle of a pavement. Seven temperature sensors (T1 to T7) were installed in the pavement structure while two (T8 and T9) were installed near the data logger (Figure 1). The temperature sensors are DS 1825 type. Water content is measured with 5 TDR probes (TDR1 to TDR5), type TRIME-PICO 32. TDR probes allow also temperature measurements. Four strain gauges were installed to measure horizontal strain, two at the bottom of asphalt layer (S3 and S4) and two (S1 to S2) in the middle of recycled layer. As strain gauge can be easily destroyed during excavation works, they were protected with bitumen tape. These sensors were developed within the EU FP6 research project SPENS ([9]). All sensors are connected with data logger with saving interval of four hours.

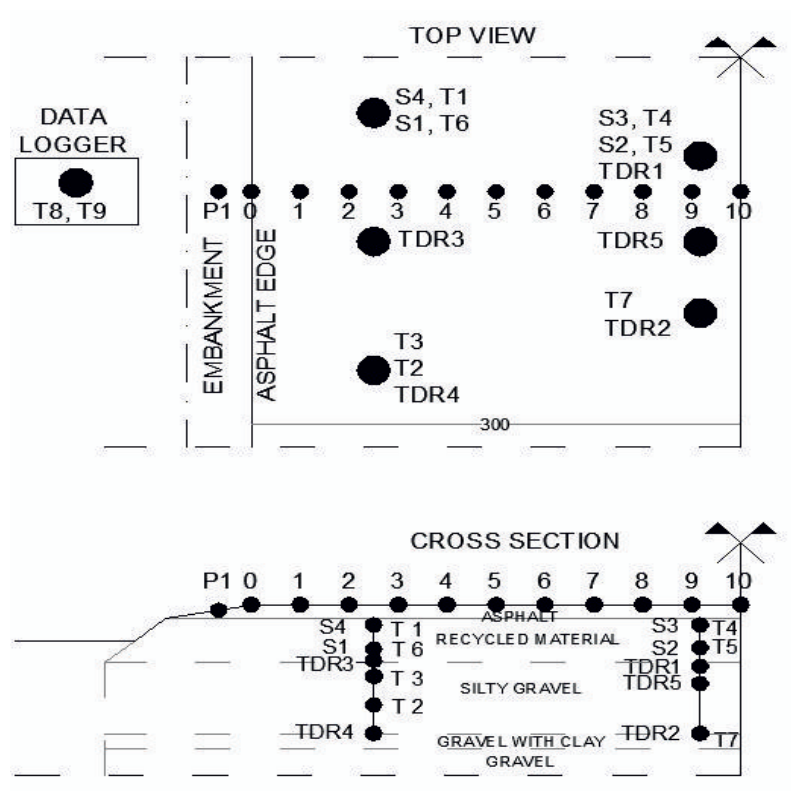

Figure 1. Sensors position in test field

After completion of asphalt protection layer geodetic measurement of vertical displacement are performed annually in 12 points ( $\mathrm{P} 1,0,1$ to 10$)$. All sensors and measuring points are presented in Figure 1.
Slovenian agency for environment (ARSO) has two weather stations (Semič and Černomelj) near the test field to monitor temperature, precipitation and snow height. Those data were used for analysis of monitoring results. They are available on the web page http://meteo.arso.gov.si.

\subsection{Material of pavement}

During the excavation works, soil samples of recycled material and old sub base layer were obtained for laboratory investigation. Results of dry density on test field, specific gravity, water permeability and sieving results are presented in Table 1 and Figure 2.

The remediation was done with cold in-situ retreatment by $3 \%$ of foamed asphalt and $1 \%$ of cement, which were mixed with old base layer $(64 \%)$ and old asphalt layer $(32 \%)$. Old base layer was fouled gravel $0 / 45 \mathrm{~mm}$.

\subsection{Installation of sensors}

Dry densities of materials were measured by sand method on compacted layers. Figure 3 shows installation of TDR probe.

Table 1. Material characteristics

\begin{tabular}{|c|c|c|c|}
\hline & & $\begin{array}{c}\text { Recycled } \\
\text { material }\end{array}$ & $\begin{array}{c}\text { Old sub } \\
\text { base }\end{array}$ \\
\hline Density & $\begin{array}{c}\rho_{d} \\
{\left[t / m^{3}\right]}\end{array}$ & 2.195 & 2.272 \\
\hline $\begin{array}{l}\begin{array}{l}\text { Particle } \\
\text { density }\end{array} \\
\end{array}$ & $\begin{array}{c}\rho_{\mathrm{s}} \\
{\left[\mathrm{t} / \mathbf{m}^{3}\right]}\end{array}$ & 2.61 & 2.72 \\
\hline $\begin{array}{c}\text { Water } \\
\text { permeability }\end{array}$ & $\begin{array}{c}\mathbf{k} \\
{[\mathbf{m} / \mathbf{s}]}\end{array}$ & $1.8 * 10^{-4}$ & $4.6^{*} 10^{-5}$ \\
\hline \multirow{3}{*}{$\begin{array}{l}\text { Particle size } \\
\text { distribution }\end{array}$} & $\begin{array}{l}\mathrm{Cu} \\
{[-]}\end{array}$ & 95.6 & 174.2 \\
\hline & $\begin{array}{l}\mathrm{Cc} \\
{[-]}\end{array}$ & 10.6 & 13.6 \\
\hline & $\begin{array}{c}<0.063 \mathrm{~mm} \\
{[\%]}\end{array}$ & 10.0 & 10.3 \\
\hline
\end{tabular}

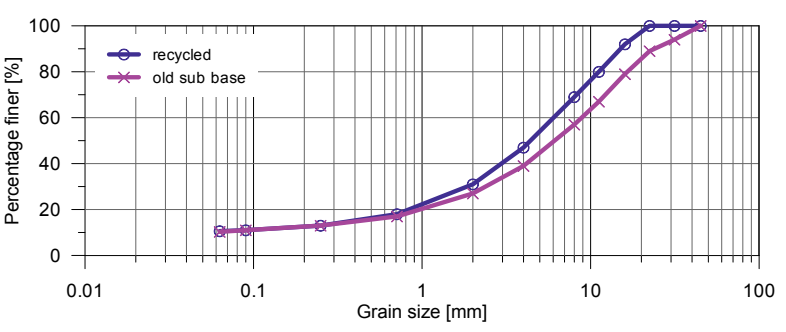

Figure 2. Grain size distribution

On Figure 4 installation of strain gauges is also presented. Long strain gauge is glued on bituminous tape, which is stabilised with two cardboard rectangles on each field, like letter $\mathrm{H}$. The cardboard rectangles enable strain gauges good contact with bedding material. Manufactured and calibrated strain gauge was then laid on the bedding layer surface on thin bitumen spot at the field. The bitumen spot is placed just in small area around strain gauge. If strain gauge is installed in the soil, then sensor is covered with excavated soil and 
compacted. In other hand, when strain gauge sensor is installed under the asphalt layer, it is protected with asphalt on upper field and then asphaltation with machine can be done. ([7])

All sensors were checked and calibrated in laboratory before installation work. Calibration of TDR probes included the effects of temperature, soil type and soil unit mass upon the measured values $([16,18,19,20,21,22$, 23]). The influence of temperature upon the measurement with strain gauges was also checked in laboratory and included into calibration. To minimize temperature effect dummy sensors were installed next to the test section.

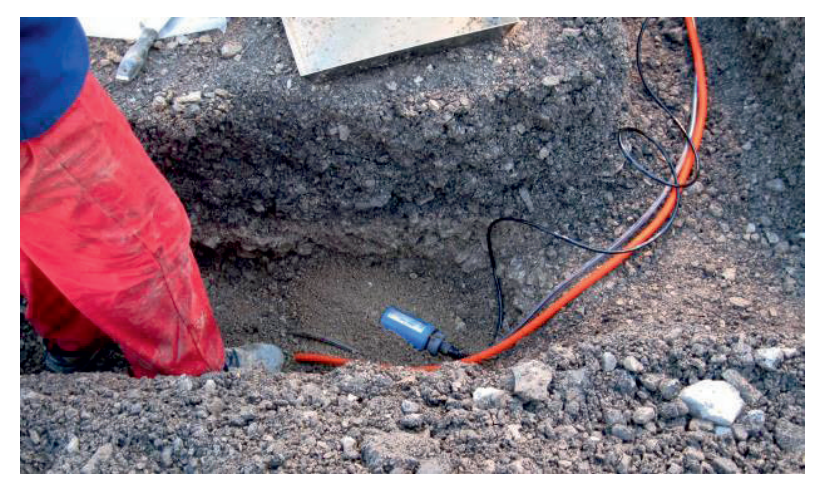

Figure 3. Installation of TDR probe.

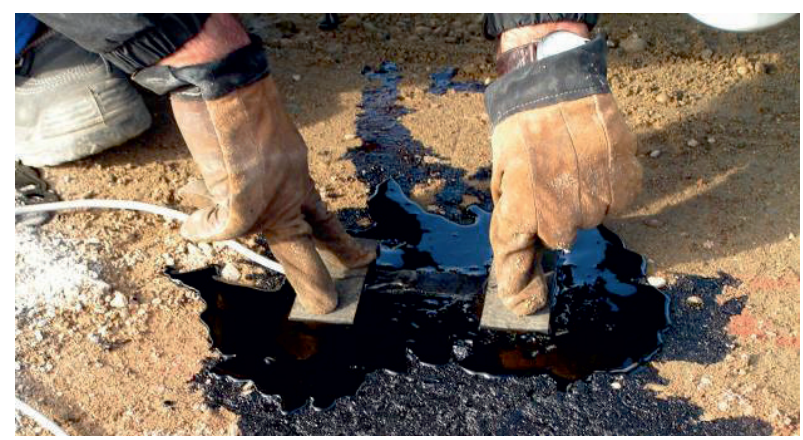

Figure 4. Installation of strain gauge.

\section{Experimental results}

In the Figure 5 and Figure 6 all monitored data are presented. While many sensors of temperature were installed, all are presented but only minimum and maximum temperature recorded on weather station are showed in legend. Temperatures in the pavement are between daily minimum and maximum air temperature, only two sensors during summer times recorded higher temperature. Those two sensors T8 and T9 are installed in data logger covered with iron plate.

The frost can be detected like suddenly fall in volumetric water content on the diagram of water content. This happened in December 2011 for all probes and in January 2015 only in recycled layer. During the whole monitoring period volumetric water content in all layers grow to the predicted value of saturation state after longer rainfall period.

Horizontal strains that were measured in recycled layer by strain gauges are low. However some findings can be observed. Main changes are recorded under the wheel tracks during winter times. After five years of strains monitoring at the bottom of asphalt layer (S4) the edge zone showed compression behaviour, while in recycled layer in the edge zone (S1) strains have increased slowly to extension of $0.5 \%$.

Horizontal strains in recycled layer in the middle zone (S2) have shown almost no change, while S3, which has been installed at the bottom of asphalt layer has failed.

Geodetic measurements of vertical displacement at the surface show that whole pavement settled down. While embankment and edge zone (width of $1 \mathrm{~m}$ ) of road surface settles for 10 to $18 \mathrm{~mm}$, the centre zone settles no more than $6 \mathrm{~mm}$.
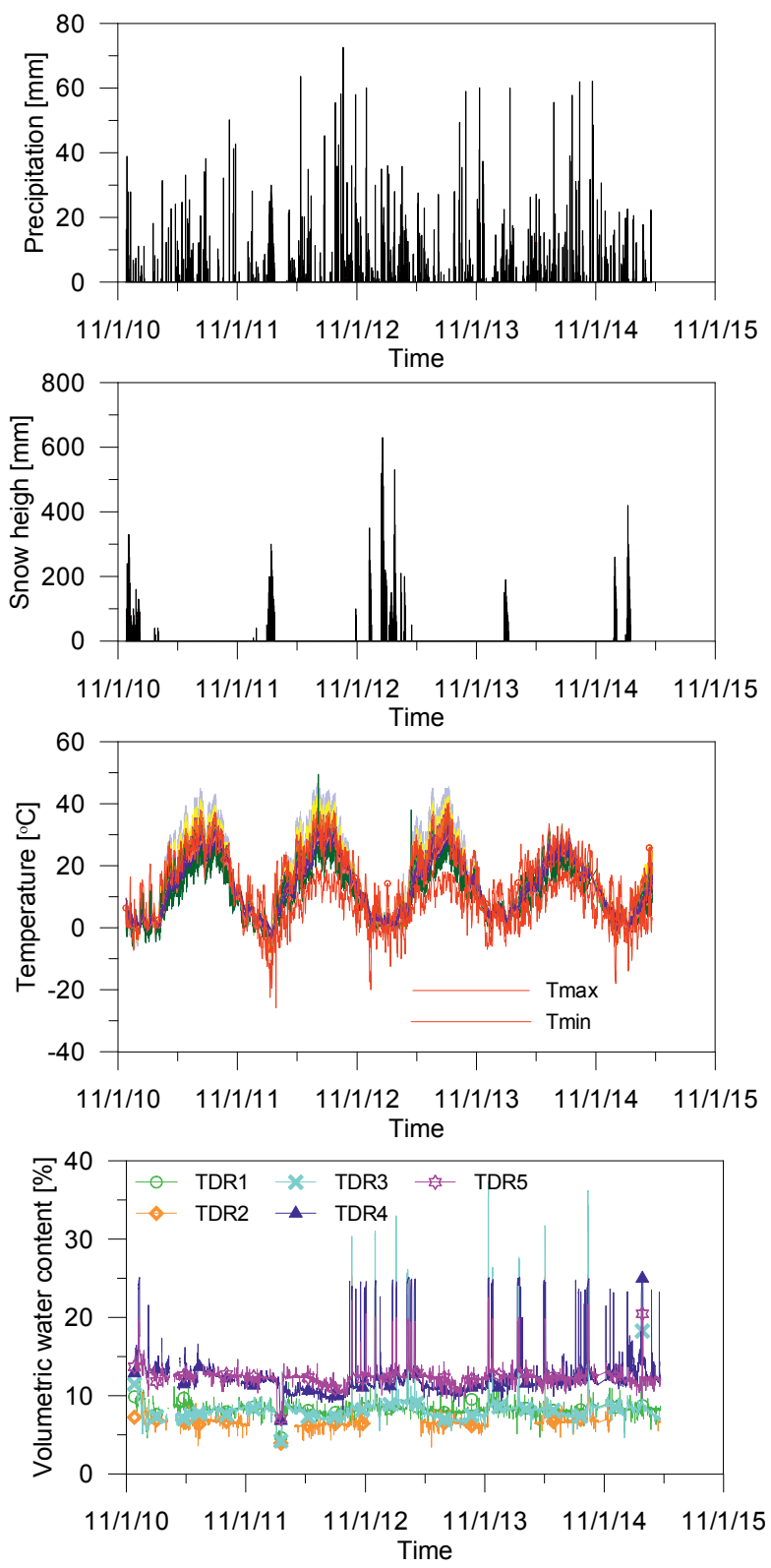

Figure 5. Precipitation, snow height, temperature and volumetric water content against time. 

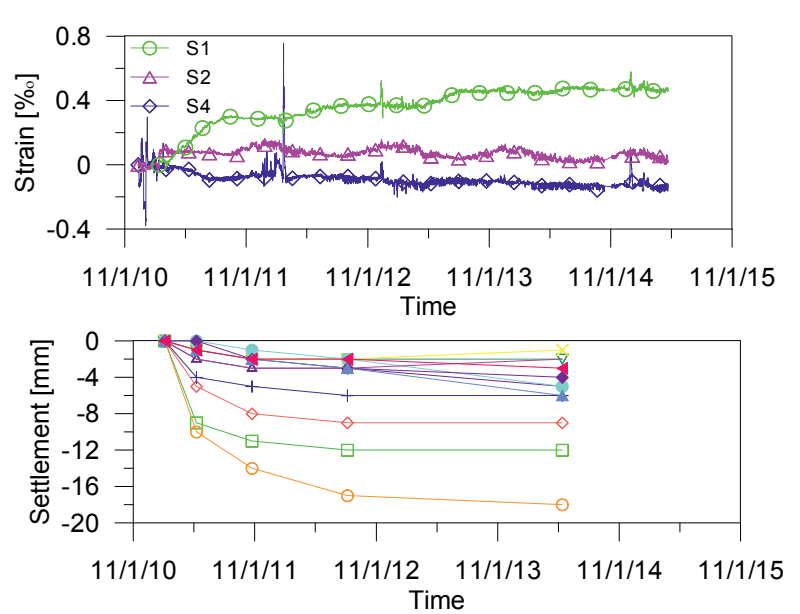

\begin{tabular}{|llllllll|}
\hline$\square$ & $\mathrm{P} 1$ & - & 2 & $\times$ & 5 & - & 8 \\
$\odot$ & 0 & $\triangle$ & 3 & - & 6 & - & 9 \\
$\diamond$ & 1 & $\nabla$ & 4 & - & 7 & 4 & 10 \\
\hline & & &
\end{tabular}

Figure 6. Strains and settlement against time.

During winter, when also underground temperatures fall under zero, soil start freezing (Figure 7). It is observed for recycled layer, that freezing starts when temperature in pavement is at least few days under zero. At the freezing point the TDR probes show value between 4 to $7 \%$. Another effect can be observed during the thawing which starts when temperature reach around $-2{ }^{\circ} \mathrm{C}$. Water content on the edge grows more than water content in middle part of pavement. Values of volumetric water content in recycled layer and in the old sub base layer in the middle zone of pavement are higher after thawing than before freezing. Described mechanism is known as thaw weakening, while during the freezing time water from deeper depths drawn up to the shallow frost zone. After spring thawing, water content in the layer increases in some cases to saturated value $([2,8])$. Sensor TDR3 expresses described mechanism. TDR2 sensor shows some problems during this winter. August and September 2014 had many rainy days with high values of precipitation. When daily precipitation exceeds $20 \mathrm{~mm}$, the old sub base layer on the edge part of pavement reached predicted full saturation value of volumetric water content (Figure 8). While the TDR probes were installed in finer material than the layer materials are and the real values of dry density around the probes are not know, it is not possible to speak about saturation ([15]). Values of volumetric water content for old sub base layer never exceed $26 \%$, which lead to prediction that this value correspond to full saturation state. Same prediction could be done for recycled layer, but value of saturation volumetric water content is $36 \%$. After few days of daily precipitation higher than $20 \mathrm{~mm}$ in all measuring points increase of volumetric water content is observed. In old sub base layer predicted full saturation is reached.

The same is observed for recycled layer on the edge part of the pavement; while in the middle part of the pavement the increase of volumetric water content for about $20 \%$ is observed. Recycled layer is protected with asphalt layer and water from precipitation flow from middle part to the edge part, where drainage is not regulated. Thus, volumetric water content is higher in the edge part of the pavement compared to the rest of the pavement. Similarly, also other authors observe that water content in unbound layers is highly dependent on permeability properties of asphalt layer ([10]) as well as permeability properties of cold in-situ retreatment with foamed bitumen layer ([4]). (a)

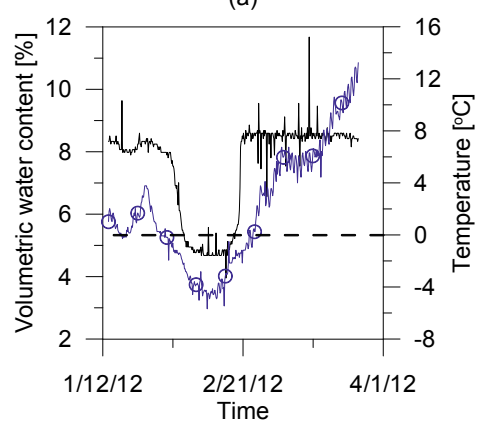

(d)

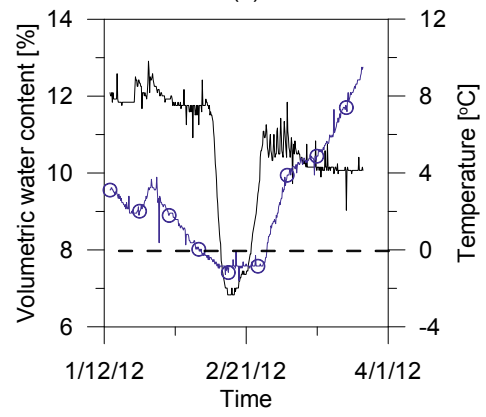

(b)

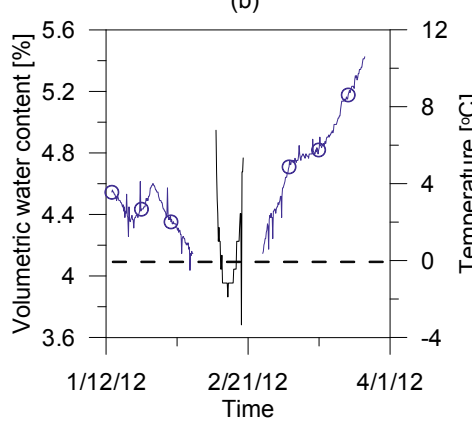

(e)

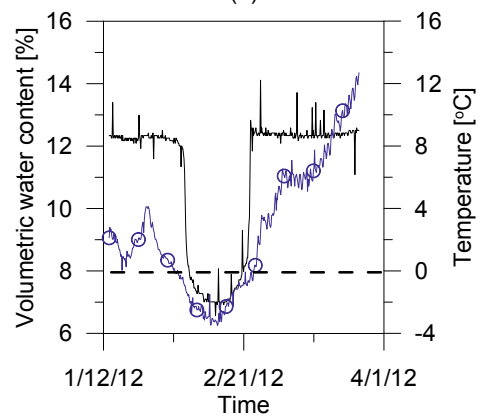

(c)

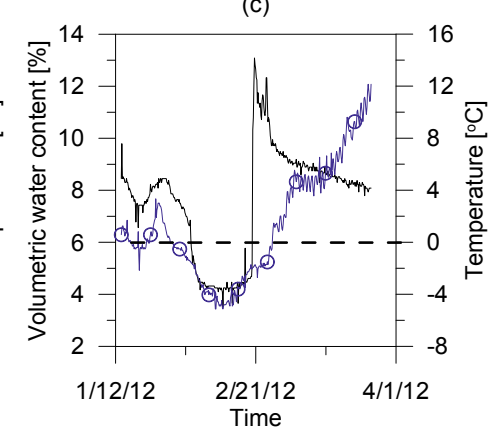

Legend

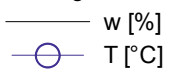

Figure 7. Freezing period for each TDR probe: (a) TDR1, (b) TDR2, (c) TDR3, (d) TDR4 and (e) TDR5. 

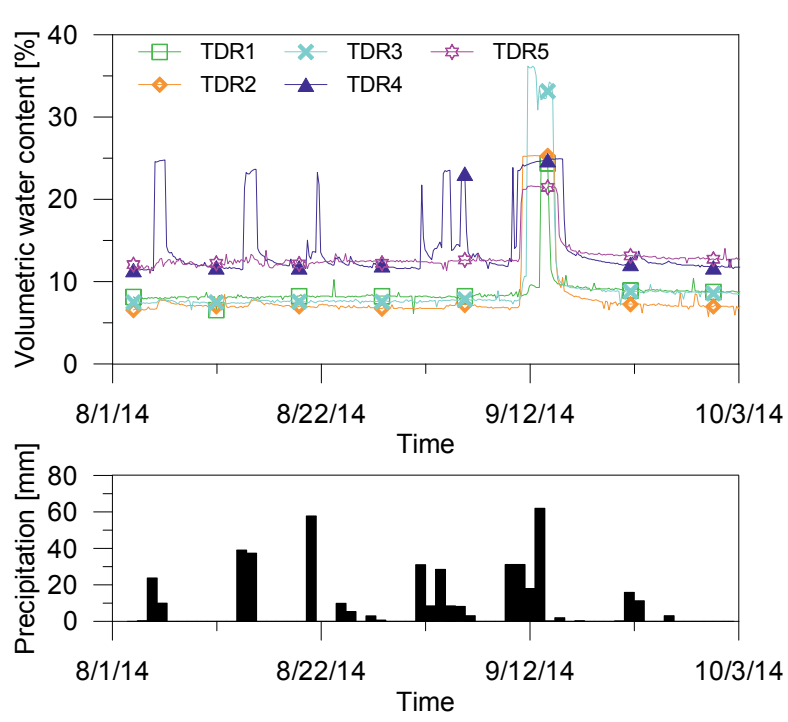

Figure 8. Relation between volumetric water content and precipitation (August and September 2014).

The same water flow is observed during melting of snow (Figure 9). Water from melting of snow is firstly recorded in edge zone of old sub base layer. After few days water start to penetrate in the middle zone of old sub base layer and also in the edge zone in recycled layer. The TDR probe in the middle zone of recycled layer does not record any water change due to melting of snow, and thus gives an assumption that protection with asphalt layer is enough impermeable.
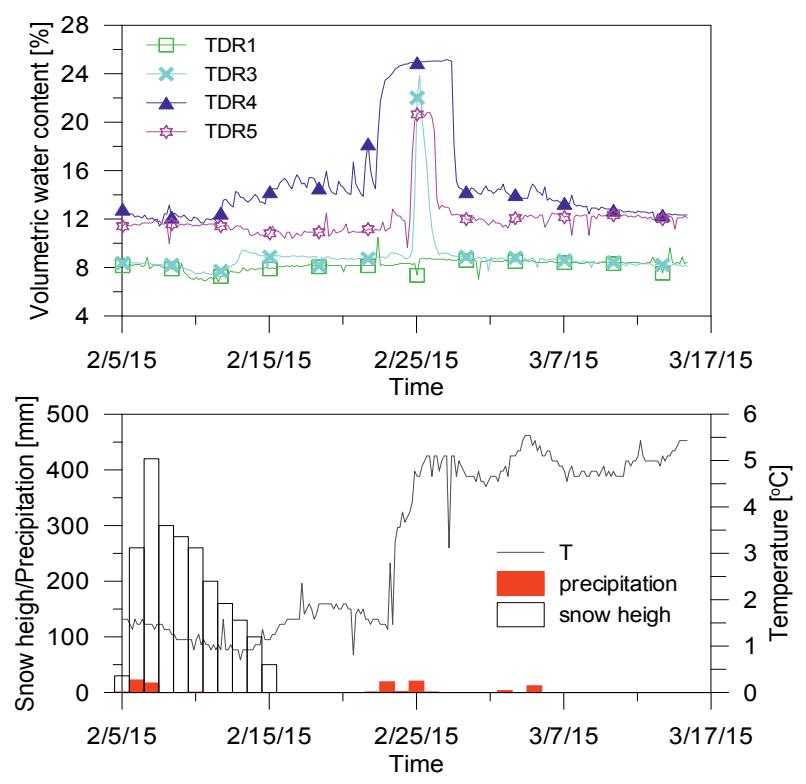

Figure 9. Relation between volumetric water content and melting of snow (February 2015).

Figure 10 and Figure 11 represent relation between deformation and temperature measured by strain gauges. In February 2012 horizontal strain increase after temperature exceeds $0{ }^{\circ} \mathrm{C}$. At this time freezing was also observed. Thawing corresponds to extension at the bottom of asphalt layer in the edge zone. During thawing time water content in soil increase and this leads to extension in recycled layer. Different behaviour is recorded in December 2012 under asphalt layer and in the recycled layer, while in the middle zone only yearly changes are recorded. During winter times strains increased, while during summers returns almost to the start value (Figure 6). Very small changes can be influenced by temperature response of strain gauges. Other sensors show increasing of strain when temperatures decrease less than zero and when temperatures start increasing strains decrease to the values $0.02 \%$ o lower than before freezing. During freezing time extension in recycled layer is present and during thawing compression is recorded.

This behaviour corresponds to ice lenses formation. While temperature in top falls under zero, water from under layer starts penetrating to surface. Bituminous protection type of strain gauge prevents water to penetrate higher and in the case of temperature lower than $0{ }^{\circ} \mathrm{C}$, ice lenses start creating under strain gauge which leads to extension. During all five years of monitoring a small compression is observed under asphalt layer, which is in contrast with [5] observations. In the case of explaining deformation under the wheel tracks, extension at the bottom of asphalt layer is presented. In this way, freeze-thaw cycles dominate on strain response.

Measurements of vertical displacements show that edge zone of pavement settle more than the middle zone. Traffic load on new or rebuilt pavement can causes higher settlements of road surface $([5,14])$ as well as frequent and high volumetric water content changes ([2, $8,10])$. While settlements have been measured only few times out of the freezing period and not continuously during the whole monitoring period, results do not capture possible heaving due to freezing. Furthermore, it is difficult to decide about the reason for settlements. On the authors opinion, measured settlements are caused mostly by the traffic loading.

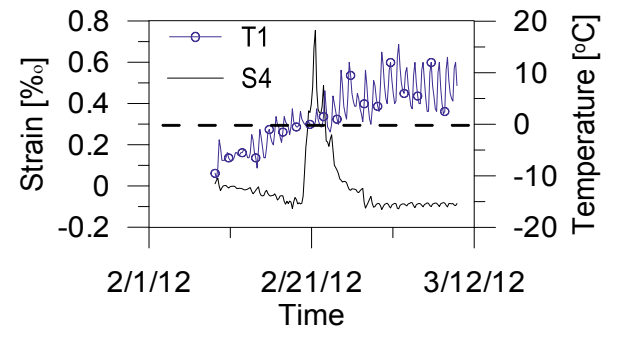

Figure 10. Relation between deformation and temperature (February 2012).
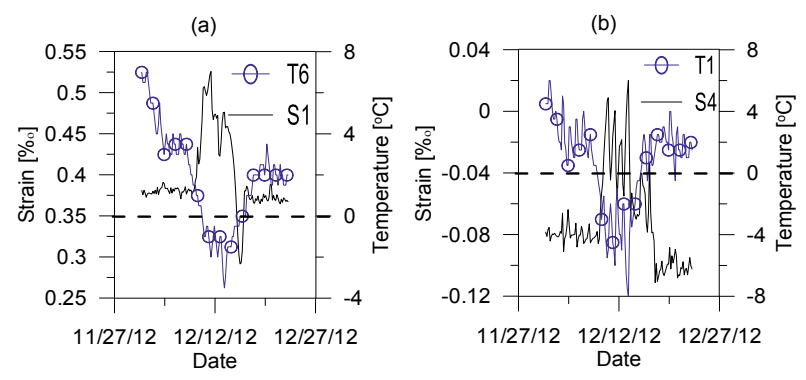

Figure 11. Relation between deformation and temperature (December 2012): (a) recycled layer and (b) under asphalt. 


\section{Conclusions}

This paper describes hydraulic and deformation observation in pavement at National road in Slovenia during five years. The monitoring system improves knowledge about water transition in pavement and freezing depth. Presented results in this work also enable to compare behaviour of in-situ cold retreatment layer with fouled old sub base layer.

The remediation work of old pavement was done with cold in-situ pavement retreatment using foamed bitumen and cement. While this is not a common solution in Slovenia it was expected, that recycled layer would reduce the freezing depth. With recorded data it is observed that freezing depth is still $80 \mathrm{~cm}$, when temperatures in pavement are at least 5 days under zero. Freezing process leads to extension horizontal strain at the bottom of asphalt layer and also in recycled layer, while thawing cause compression. Horizontal deformation at the bottom of asphalt layer after five years becomes lightly compression and in recycled layer extension in edge zone. This behaviour corresponds to geodetic measurements of surface settlements, which cause higher settlement in edge zone than in the middle zone. At least no cracks are observed on asphalt surface after five years which corresponds to small recorded deformations in recycled layer.

High values of water content are reached in the whole pavement. The main reason is no drainage system. The water from precipitation and melting of snow penetrates from edges to the middle part of pavement, firstly in old sub base layer. In case of few days high precipitation old sub base layer becomes saturated and water start penetrating to recycled layer, while no drainage is in pavement.

\section{Acknowledgements}

The preparation of this work was assisted by author's participation within the COST Action TU1202 and a short research visit of a first author at ENCP. Authors are very grateful for this opportunity.

\section{References}

1. N. Bandara, T.H. Binoy, H.S. Aboujrad, Cold Regions Engineering 2015, 135 (2015)

2. P.J. Becker, D.J. White, P.K.R. Vennapusa, M.J. Dunn, Transportation Research Board (2014)

3. T. Cackler, D.J. White, R.L. Handy, P.K.R. Vennapusa, CEER Research Project (2014)

4. M. Iwanski, P. Buczynski, G. Mazurek, Sustainability, Eco-efficiency and Conservation in Transportation Infrastructure Asset Management Losa \& Papagiannakis (2014)

5. D. Jones, R. Wu, S. Louw, TRR Journal 2462, 126 (2014)

6. W. Li, M. Pour-Ghaz, J. Castro, J. Weiss, J. Mater. Civ. Eng. 24, 299 (2012)

7. O. Maadani, A.O. Abd El Halim, N. Mostafa, J. Cold Reg. Eng. (to be published, 2014)
8. E. Simonsen, U. Isacsson, Cold Regions Science and Technology 29, 135 (1999)

9. M. Tušar, M. Ravnikar Turk, L.G. Wiman, D. Kokot, S. Lenart, E. Kemperle, E., Brussels: European commission, DG research, (2011)

10. Z. Wen, M. Zhang, W. Ma, Q. Wu, F. Niu, Q. Yu, Z. Fan, Z. Sun, European Journal of Environmental and Civil Engineering 19, 387 (2014)

11. D.J. White, P.K.R. Vennapusa, P. Becker, C. White, CEER Research Project (2013)

12. H. Xu, J.D. Spitler, Renewable Energy 72, 1 (2014)

13. X.Z. Xu, J.C. Wang, Y.S. Deng, (2010). Thermophysic of Frozen Soil. Science Press, Beijing 113 (in Chinese)

14. F. Yu, J. Qi, X. Yao, Y. Liu, Engineering Geology 160, 44 (2013)

15. A.M. Tang, A.N. Ta, Y.J. Cui, J. Thiriat, GTJ 32, 1 (2009)

16. G.C. Topp, J.L Davis, A.P. Annan, Water Resources Research 16, 574 (1980)

17. W.A. Take, D.N. Arnepalli, R.W.I. Brachman, R.K. Rowe, OttawaGeo 2007, 1865 (2007)

18. T.V. Duong, A.M. Tang, Y.J. Cui, V.N. Trinh, N. Calon, Geotech. Test. J. 36, 55 (2013)

19. T.V. Duong, Y.J. Cui, A.M. Tang, J.C. Dupla, N. Calon, Can. Geotech. J. 51, 735 (2014)

20. O.H. Jacobsen, P. Schjonning, Journal of Hydrology 151, 147 (1993)

21. J. Stolte, J.M. Halbertsina, M. Veerman, G.J. Wösten, J.H.M. Freijer, J.I. Bouten, W. Dirksen, C.Van Dam, J.C. Van den Berg, Soil Science Society of Americal journal 58, 1596 (1994)

22. Y. Gong, Q. Cao, Z. Sun, Hydrological Processes 17, 3601 (2003)

23. J.M. Schneider, D. Fratta, Can. Geotech. J. 46, 753 (2009)

24. TSC 06.5012:2003, Projektiranje klimatski in hidrološki pogoji 